\title{
Leukoplakia of Lip
}

National Cancer Institute

\section{Source}

National Cancer Institute. Leukoplakia of Lip. NCI Thesaurus. Code C3951.

A clinical term that indicates the presence of a white patch on the surface of the lip which cannot be characterized as any other disease. It may be a precancerous condition and in most cases histologic examination reveals keratosis. 